\title{
Value of an Oral Elemental Diet During Induction Therapy of Ulcerative Colitis with Infliximab: a Pilot Study
}

\author{
A Horiuchi*, M Tamaki, M Kajiyama, N Tanaka \\ Digestive Disease Center, Showa Inan General Hospital, Komagane, Japan
}

\begin{abstract}
Received: September 28, 2016; Accepted: October 14, 2016; Published: October 18, 2016
*Corresponding author: Akira Horiuchi, M.D, Digestive Disease Center, Showa Inan General Hospital, 3230 Akaho, Komagane, Japan, 399-4117, Phone: +81-265-82-2121; Fax: +81-265-82-2118; E-mail: horiuchi.akira@sihp.jp
\end{abstract}

\begin{abstract}
Aim: We evaluated the effects of an orally administered elemental diet during induction therapy with infliximab in patients with ulcerative colitis.

Method: Between January 2011 and March 2016, consecutive patients with active ulcerative colitis receiving induction therapy with infliximab were studied. The initial group received peripheral intravenous fluid therapy (IV group). A subsequent group received an elemental diet orally (Elental $®$ ) plus intravenous fluid therapy (EN-IV group). The stool frequency and clinical response outcomes were retrospectively evaluated at 2 weeks following the first infusion of infliximab $(5 \mathrm{mg} / \mathrm{kg})$.

Results: Twenty-eight patients ( 16 women, median age 39 years) were enrolled, 12 in the IV group and 16 in the EN-IV group. The patients' demographic characteristics were similar. Seven patients $(58 \%)$ in the IV group and $13(81 \%)$ in the EN-IV group achieved clinical response $(\mathrm{P}=0.18)$. At 2 weeks following the first infusion of infliximab, there was significantly greater reduction in Simple Clinical Colitis Activity Index [1 (1-3.5) vs. 2.5 (1.8-6.5), P=0.045] and maintenance of serum albumin levels [3.9 (3.5-4.2) vs. 3.2 (3-3.5), $\mathrm{P}=0.0039]$ in the enteral group vs. the IV group. Finally, the duration of hospitalization in the EN-IV group was significantly shorter than the IV group [0 [3.5-9.3] days vs. 8[15-21] days, $\mathrm{P}=0.0012]$.
\end{abstract}

Conclusion: Oral ingestion of an elemental diet resulted in a reduction in hospitalization, and an improved clinical response and serum albumin level compared with IV fluid therapy during induction therapy with infliximab for ulcerative colitis.

Keywords: Ulcerative Colitis; Induction Therapy; Infliximab; Elemental Diet; Albumin

\section{Abbreviations}

IV group; Peripheral Intravenous Fluid Therapy Group; EN-IV Group, Elemental Diet Orally (Elental@) Plus Intravenous Fluid Therapy Group.

\section{Introduction}

An extremely low fat, palatable elemental diet containing amino acids is commercially available in Japan where it is approved for the nutritional management of patients with pancreatic disease $[1,2]$. Nutrition therapy with elemental diets has been reported to significantly reduce mucosal inflammation and improve clinical and endoscopic disease activity and mucosal cytokine levels when used as a first-line therapy of Crohn's disease $[3,4]$. Prior studies with enterally administered elemental diets have also reported histologic improvement in patients with eosinophilic esophagitis [5], a reduction of symptoms in patients with chronic pouchitis [6], and reduced diarrhea in gastrostomyfed patients [7].

The role of elemental diets in the management of ulcerative colitis remains unclear [6, 8]. Axelsson et al. previously reported remission of disease activity in $44 \%$ of 34 patients with inflammatory bowel diseases (23 patients with ulcerative colitis and 11 patients with Crohn's disease) associated with the use of an elemental diet administered as a tube feeding. Six of 13 patients with ulcerative colitis treated with elemental diet remained well for 7-28 months [9].

Induction therapy using infliximab in ulcerative colitis patients has been associated with frequent defecation and a reduction in serum albumin levels $[10,11]$. We hypothesized that oral ingestion of an elemental diet during induction therapy with infliximab for ulcerative colitis would reduce the need for intravenous therapy and result in a reduction in diarrhea. The aim of this pilot study was to evaluate the effects of oral administration of an elemental diet during induction therapy with infliximab in patients with active ulcerative colitis.

\section{Method}

\section{Patients}

Consecutive patients with moderate to severe ulcerative colitis receiving induction therapy using infliximab at the Showa Inan General Hospital were enrolled from January 2011 to March 2016. The first group of patients (from January 2011 to August 2013) received traditional induction therapy plus peripheral intravenous fluid therapy alone (IV group). The subsequent group received induction therapy plus the orally administered 
elemental diet in addition to intravenous fluid therapy (EN-IV group) from September 2013 to March 2016.

\section{Study design}

This is a case-control pilot study, based on historical comparisons of patients in two time periods, with data being collected retrospectively. The Institutional Review Board of this hospital approved the retrospective analyses. All enrolled patients reported the average number of bowel movements/per day to doctors and underwent blood testing at least once a week during induction therapy, irrespective of hospitalization. Each patient was told to record the number of bowel movements/ per day before the start of induction therapy. The determination of defecation frequency and clinical response outcomes was based on a retrospective review of the patients' charts with special attention to clinical symptom and the laboratory data before and after induction therapy. The frequency of defecation and clinical response outcomes were retrospectively compared in both groups before and on day 14 after the first infusion of infliximab (5 mg/kg) $[12,13,14]$. Endoscopic and histological examinations were performed within 1 week before and 2-4 weeks after the start of the induction therapy. Disease activity was defined according the endoscopic Mayo Score $[12,13]$ and Simple Clinical Colitis Activity Index [14]. Clinical response was decided as a total score of Simple Clinical Colitis Activity Index $\leq 4$ points on day 14 after the first infusion of infliximab. Based on these results it was decided whether the second infusion of infliximab would be required. Data required for calculation of the activity scores were prospectively recorded.

\section{Elemental diet used}

A commercially available predigested elemental diet, Elental ${ }^{\circledR}$ (1 kcal/mL, EA Pharma Co., Ltd., Tokyo, Japan) consisting of $16.5 \%$ protein (provided as amino acids), $79.5 \%$ carbohydrates (provided as dextrin, mean molecular weight 900), 0.64\% fat, and $3.36 \%$ vitamins and minerals dissolved in water to yield 1 $\mathrm{kcal} / \mathrm{mL}$ was used.

\section{Diet and fluid therapy}

The IV group received peripheral IV fluid therapy $\left(\mathrm{Na}^{+} 35 \mathrm{mEq} / \mathrm{L}, \mathrm{K}^{+} 20 \mathrm{mEq} / \mathrm{L}, \mathrm{Cl}^{-} 35 \mathrm{mEq} / \mathrm{L}, \mathrm{L}^{-}\right.$-lactate $-20 \mathrm{mEq} / \mathrm{L}$, glucose $75 \mathrm{~g} / \mathrm{L})(840 \mathrm{kcal} / 2000 \mathrm{~mL} /$ day-1050 kcal/2500 mL/ day) with intake of only liquids (tea or sport beverages) for the first week and then received a low residue diet (800-1000 kcal/ day) with tapering of the amount of IV fluid during the second week. All patients in this group were hospitalized for at least one week.

In EN-IV group all patients received the orally administered elemental diet (Elental $囚$ ) for at least 7 days with intake of only liquids and then received low residue diet or regular diet $(800-1000 \mathrm{kcal} /$ day) for the second week, irrespective of hospitalization. In the EN-IV group 11 patients also received IV fluids $(210 \mathrm{kcal} / 500 \mathrm{~mL} /$ day) for 1 to 4 days in the outpatient clinic. The remaining 5 patients were hospitalized and received IV fluid therapy (420 kcal/1000 mL/day) for 7 days. All patients in the two groups were scheduled to receive the total calorie of 800-1000 kcal/day for two weeks after the start of induction therapy. The estimated total calorie intake/day for 2 weeks after the start of induction therapy was calculated for each patient. Twelve hospitalized patients of the two groups received intravenous antibiotics. No steroids, immunosuppressive drugs, or anti-motility drugs were administered.

\section{Statistics}

The study size is based on a comparison of patients from two consecutive time periods. Data was collected retrospectively. All data are expressed as median (Interquartile range). Statistical tests to compare the measured results for the two groups were as follows: the Chi-square test, with Yates' correction for continuity where appropriate, was used for comparison of categorical data. Fisher's exact test was used when the numbers were small. For nonparametric data, Mann-Whitney test was used when 2 means were compared. A paired $t$ test was used to compare the parametric data before and after induction therapy in the two groups. Statistical analysis was performed by using SAS 9.2 (SAS Institute Japan).

\section{Results}

Twenty-eight patients were enrolled including 12 in the IV group. The EN-IV group included 16 patients. The patients' demographic characteristics were similar between the two groups (Table 1). Seven patients (58\%) in the IV group and 13 patients $(81 \%)$ in the EN-IV group achieved clinical response (total score of Simple Clinical Colitis Activity Index $\leq 4$ points). Four patients (two in the IV group, two in the EN-IV group) who had no response underwent surgery while the remaining 4 patients (one in the IV group, three in the EN-IV group) were successfully remitted by tacrolimus. Elemental diet was orally taken four or six times/day and the total intake of elemental diet was [median (Interquartile range)] 900 (600-900) kcal/day for 8 (7-10) days (Table 1). For two weeks after the start of induction therapy, the estimated total calorie intakes/day were similar in both groups [900(900-1000) vs. 1000(900-1062), $\mathrm{P}=0.25]$. The duration of IV fluid and the duration of hospitalization in the ENIV group were significantly shorter than those of the IV group, respectively [3.5 (1-7) vs. 9 (7-15.8), $\mathrm{P}<0.0001 ; 0$ (3.5-9.3) days vs. $8(15-21$ ) days, $\mathrm{P}=0.0012$ (Table 1 ).

When clinical data was compared between before and after induction therapy, stool frequency, endoscopic Mayo Score, and Simple Clinical Colitis Activity Index were all significantly reduced in both groups following the first infusion of infliximab (Fig.1abc). Serum albumin level was maintained in the ENIV group whereas it was significantly reduced in the IV group 2 weeks after initiation of induction therapy (Fig.1d). The hemoglobin significantly remained unchanged in both groups (data not shown). C-reactive protein value was significantly reduced after induction therapy in both groups. When clinical data was compared between two groups before and 2 weeks after the first infusion of infliximab, stool frequency in EN-IV group was less than that of IV group [3 (2.3-3.8) vs. 4.5 (2.8-6.8), $\mathrm{P}=0.073$ ] (Table 2). Endoscopic Mayo Score and Simple Clinical Colitis Activity Index Score were significantly better in EN-IV group than in IV group [0 (0-1) vs. 1 (0.75-2), $\mathrm{P}=0.042$; (1-3.5) vs. $2.5(1.8-6.5), \mathrm{P}=0.045]$. The serum albumin level in those 
Table 1: Baseline characteristics and clinical outcomes of 28 patients enrolled in this study

\begin{tabular}{|c|c|c|c|}
\hline Group & $\begin{array}{l}\text { EN-IV } \\
(\mathrm{N}=16)\end{array}$ & $\begin{array}{l}\text { IV } \\
(\mathrm{N}=12)\end{array}$ & $\mathbf{P}$ \\
\hline Gender, female & $10(63 \%)$ & $6(50 \%)$ & 0.51 \\
\hline $\begin{array}{l}\text { Age, years, median } \\
\text { (IQR) }\end{array}$ & $40(35.3-56.8)$ & $39(35-48)$ & 0.35 \\
\hline $\begin{array}{l}\text { Body weight, kg, median } \\
\text { (IQR) }\end{array}$ & $46.5(42.3-58.8)$ & $49(46-55)$ & 0.52 \\
\hline $\begin{array}{l}\text { Disease duration, years, } \\
\text { median (IQR) }\end{array}$ & $3(1.3-5.8)$ & $2(0.9-4.3)$ & 0.48 \\
\hline $\begin{array}{l}\text { Left-sided colitis/ } \\
\text { Pancolitis }\end{array}$ & $0(0 \%) / 16(100 \%)$ & $0(0 \%) / 12(100 \%)$ & \\
\hline $\begin{array}{l}\text { Corticosteroid } \\
\text { refractory }\end{array}$ & $10(63 \%)$ & $8(67 \%)$ & 0.82 \\
\hline Clinical response* & 13(81\%) & 7(58\%) & 0.18 \\
\hline $\begin{array}{l}\text { Hospitalization } \\
\text { duration, days, median } \\
\text { (IQR) }\end{array}$ & $0(3.5-9.3)$ & $8(15-21)$ & 0.0012 \\
\hline $\begin{array}{l}\text { IV fluid therapy } \\
\text { duration, days, median } \\
\text { (IQR) }\end{array}$ & $3.5(1-7)$ & $9(7-15.8)$ & $<0.0001$ \\
\hline $\begin{array}{l}\text { Elemental diet } \\
\text { ingestion, days, median } \\
\text { (IQR) }\end{array}$ & $8(7-10)$ & 0 & $<0.0001$ \\
\hline $\begin{array}{l}\text { Elemental diet intake, } \\
\text { calorie/day, median } \\
\text { (IQR) }\end{array}$ & $900(600-900)$ & 0 & $<0.0001$ \\
\hline $\begin{array}{l}\text { Estimated total calorie } \\
\text { intake/day**, median } \\
\text { (IQR) }\end{array}$ & $900(900-1000)$ & $1000(900-1062)$ & 0.25 \\
\hline \multicolumn{4}{|c|}{$\begin{array}{l}\text { IV, intravenous; EN-IV group, an elemental diet orally (Elental }{ }^{\circledR} \text { ) in } \\
\text { addition to intravenous fluid therapy; IV group, peripheral intravenous } \\
\text { fluid therapy alone } \\
\text { * means total score of Simple Clinical Colitis Activity Index } \leq 4 \text { points. } \\
* * \text { means the data for two weeks after the start of induction therapy } \\
\text { with infliximab. } \\
\text { IQR, Interquartile Range; Values are numbers (\%) of patients except } \\
\text { for age, disease duration, hospitalization duration, IV fluid therapy and } \\
\text { elemental diet ingestion. }\end{array}$} \\
\hline
\end{tabular}

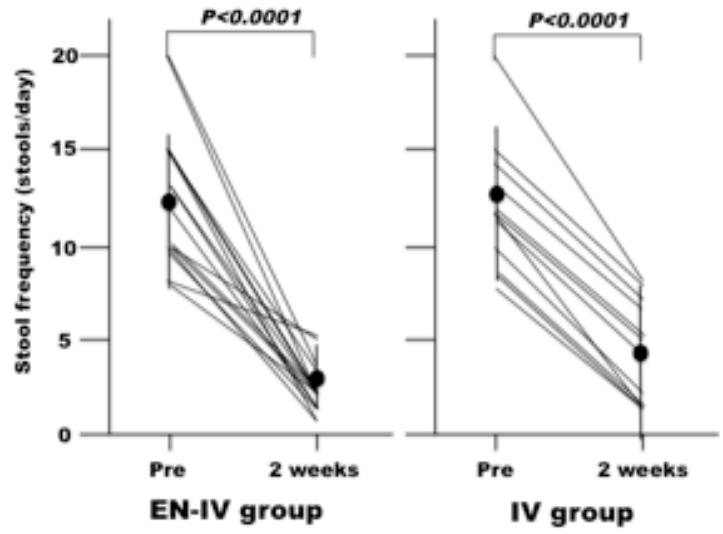

Figure 1A: Each patient before and 2-4 weeks after the first infusion of infliximab are shown; Changes of stool frequency; The closed dots and line represent the mean $\pm \mathrm{SD}$.
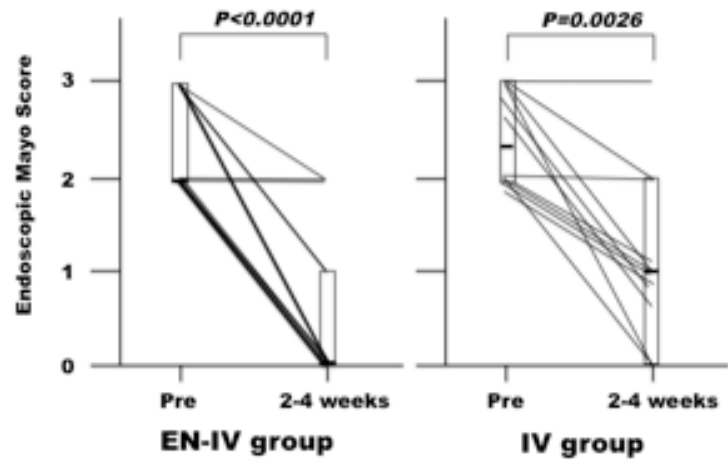

Figure 1b: Endoscopic Mayo Score; Box plots show the median (solid line within box) and interquartile range (upper and lower box boundaries).
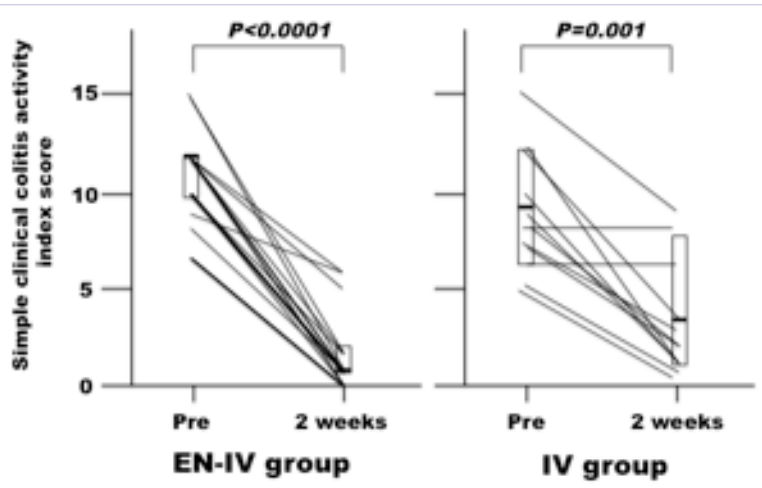

Figure 1C: Activity Index Score; Box plots show the median (solid line within box) and interquartile range (upper and lower box boundaries).

receiving elemental diets was maintained significantly higher than that in the IV group during induction therapy [3.9 (3.5-4.2) vs. 3.2 (3-3.5), $\mathrm{P}=0.0039$ ]. C-reactive protein level decreased similarly in the two groups, but the difference was not significant.

\section{Discussion}

This pilot study suggests that the addition of orally administered elemental diets can significantly shorten the duration of hospitalization when used with infliximab induction therapy for ulcerative colitis compared to use of IV fluids alone (Table 1). In addition, use of an orally administered elemental diet was associated with an improved clinical response and maintenance of serum albumin levels compared with IV therapy alone during induction therapy with infliximab (Table 2).

Although infliximab, a chimeric monoclonal antibody against tumor necrosis factor alpha is an effective therapy for introduction and maintenance of remission in ulcerative colitis [15], a significant percentage of patients who respond initially experience loss of response during therapy. On proposed mechanism is related to loss of infliximab into feces in patients with moderate-to-severe ulcerative colitis [10]. Infliximab 
clearance is also significantly increased by low serum albumin level, resulting in short half-life and decreased troughs of infliximab [11]. This study showed that oral elemental diet therapy during induction therapy prevented the decrease in serum albumin levels which may be in part responsible for the better clinical response outcomes in the EN-IV group than those of the IV group. In addition, oral ingestion of elemental diet during induction therapy enabled patients with moderate-tosevere ulcerative colitis to reduce the duration of hospitalization.

Elemental diet feeding has been reported to remit Crohn's disease in Japanese patients [3]. Because the beneficial effects of elemental diet were thought to have an anti-inflammatory effect for the small intestine but not the large intestine, elemental diets were not used for patients with ulcerative colitis [8]. In addition, it was reported that an effect on inflammation could not be

Table 2: Comparison of clinical data between an oral elemental diet in addition to iv fluid therapy group and iv fluid therapy alone group before and after induction therapy with infliximab

\begin{tabular}{|c|c|c|c|c|}
\hline Variable & & $\begin{array}{l}\text { EN-IV } \\
(\mathrm{N}=16)\end{array}$ & $\begin{array}{l}\text { IV } \\
(\mathrm{N}=12)\end{array}$ & $\mathbf{P}$ \\
\hline \multirow{2}{*}{$\begin{array}{l}\text { Stool frequency, } \\
\text { stools } / 24 \mathrm{~h}\end{array}$} & Pre & $11(10-15)$ & $12(9-14)$ & 0.73 \\
\hline & 2 weeks & $3(2.3-3.8)$ & $4.5(2.8-6.8)$ & 0.073 \\
\hline \multirow{2}{*}{$\begin{array}{l}\text { Endoscopic Mayo } \\
\text { Score }\end{array}$} & Pre & $2(2-3)$ & $2(2-3)$ & 0.93 \\
\hline & $\begin{array}{l}2-4 \\
\text { weeks }\end{array}$ & $0(0-1)$ & $1(0.75-2)$ & 0.042 \\
\hline \multirow{2}{*}{ SCCA Index } & Pre & $12(10-12)$ & $9(6-12)$ & 0.14 \\
\hline & 2 weeks & $1(1-3.5)$ & $2.5(1.8-6.5)$ & 0.045 \\
\hline \multirow[b]{2}{*}{ Hemoglobin, g/dl } & Pre & $12(9.8-13)$ & $11(9.8-12)$ & 0.37 \\
\hline & 2 weeks & $\begin{array}{l}12.8(10.6- \\
13.5)\end{array}$ & $11(9.8-12)$ & 0.081 \\
\hline \multirow{2}{*}{$\begin{array}{l}\text { Serum albumin level, } \\
\mathrm{g} / \mathrm{dl}\end{array}$} & Pre & $3.9(3.6-4.1)$ & $3.6(3.5-4)$ & 0.35 \\
\hline & 2 weeks & $3.9(3.5-4.2)$ & $3.2(3-3.5)$ & 0.0039 \\
\hline \multirow[b]{2}{*}{ CRP level, mg/dl } & Pre & $1.2(0.36-6.6)$ & $1.4(0.3-8.1)$ & 0.21 \\
\hline & 2 weeks & $\begin{array}{l}0.12(0.04- \\
0.25)\end{array}$ & $\begin{array}{l}0.11(0.08- \\
3.3)\end{array}$ & 0.81 \\
\hline
\end{tabular}

EN-IV group, an elemental diet orally (Elental $\left.{ }^{\circledR}\right)$ in addition to intravenous fluid therapy;

IV group, peripheral intravenous fluid therapy alone; CRP, C-reactive protein; SCCA Index. Simple Clinical Colitis Activity Index.

Each value shows median (Interquartile range).
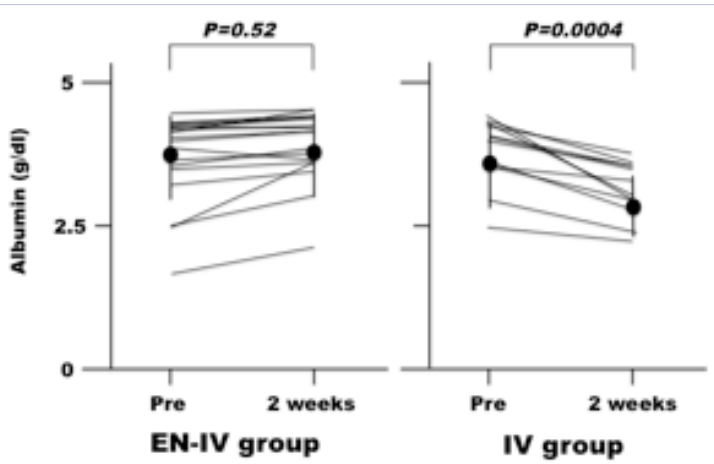

Figure 1d: Serum albumin level; The closed dots and line represent the mean \pm SD demonstrated even if elemental diet seemed to have a beneficial effect on the stage of clinical activity, especially diarrhea, in patients with ulcerative colitis [16]. However, the results of this study suggest that elemental diet may have some inhibitory effects on inflammation in patients with active ulcerative colitis. The effects of elemental diet composed of amino acids might be due to lowering of the antigenicity of the luminal contents attributed in part to the absence of whole protein, alteration of host bacterial flora, and decreasing colonic fecal bile salt load $[3,4]$.

In previous studies, a rationale for nutritionally supporting patients with active inflammatory bowel disease has been provided [17]. Patients with mild to moderate attacks can be managed with an oral conventional diet. It is recommended that no major dietary restrictions should be prescribed in active disease, except for avoidance of coarse fiber (particularly in patients with ulcerative colitis, and in the presence of bowel strictures in Crohn's disease). On the other hand, dietary restrictions are traditionally apt to be given patients with diarrhea and peripheral IV therapy is preferable in Japan. However, the estimated total calorie intakes/day were similar in both groups for two weeks after the start of induction therapy (Table 1).

The elemental diet (Elental ${ }^{\circledR}$ ) used here is a high osmolality nutrient $(1 \mathrm{kcal} / \mathrm{mL}$ equals $760 \mathrm{mOsm} / \mathrm{L})$ and is typically given at $<100 \mathrm{~mL} / \mathrm{h}$ using a pump when used for treatment of patients with Crohn's disease in Japan. However, when the elemental diet was fed at the rate of $200-300 \mathrm{~mL} / \mathrm{h}$ to gastrostomy-fed patients diarrhea did not occur in any patient [7]. A different elemental diet with the same high osmolality has been shown to be well tolerated when given intragastrically without a starter solution in patients with inflammatory bowel disease [18]. In this study, the EN-IV group had lower stool frequency compared with those in the IV group during induction therapy [3 (2.3-3.8) vs. 4.5 (2.86.8), $\mathrm{P}=0.073$ ] (Table 2).

The present studies have limitations. The study was a pilot case-control study with the small number of patients. The selection of case or control was decided based on the entry period. So we believe this study is unlikely to have critical bias to the patient selection. However, randomized studies will be required to confirm the beneficial effects of oral ingestion of elemental diet during induction therapy in patients with ulcerative colitis. The total number of calories administered during traditional Japanese therapy was less than recommended in western publications. Studies are needed to evaluate the effect of increasing the total volume and thus number of calories administered as well as direct comparison with traditional liquid nutritional supplements. This pilot study brings up many questions and additional studies are needed to confirm and extend these observations. For example, studies are need to ask whether oral use of an elemental diet can substitute for IV fluid therapy during induction therapy with infliximab which would reduce the need for hospitalization in patients with ulcerative colitis. Finally, studies are needed to identify the best time to switch from the elemental diet to standard diet after induction therapy. 


\section{Conclusion}

In conclusion, this study suggests that oral ingestion of an elemental diet resulted in a reduction in hospitalization, and an improved clinical response and serum albumin level compared with IV fluid therapy during induction therapy with infliximab for ulcerative colitis.

\section{Acknowledgments}

The authors thank David Y Graham, M.D. for his editorial advice.

\section{References}

1. Ito T, Igarashi H, Niina Y, Masayuki Hijioka, Susumu Matsuo, Yuzo Shimokawa, et al. Management of pain in chronic pancreatitis with home elemental diet ingestion. JOP J Pancreas. 2010;11(6):648-649.

2. Kataoka K, Sakagami J, Hirota M, Masamune A, Shimosegawa T. Effects of oral ingestion of the elemental diet in patients with painful chronic pancreatitis in the real-life setting in Japan. Pancreas. 2014;43(3):451457. doi: 10.1097/MPA

3. Yamamoto T, Nakahigashi M, Umegae $\mathrm{S}$, Umegae $\mathrm{S}$, Kitagawa $\mathrm{T}$, Matsumoto K. Impact of elemental diet on mucosal inflammation in patients with active Crohn's disease: cytokine production and endoscopic and histological findings. Inflamm Bowel Dis. 2005;11(6):580-588.

4. Yamamoto T, Nakahigashi M, Saniabadi AR, Iwata T, Maruyama Y, Umegae $S$, et al. Impacts of long-term enteral nutrition on clinical and endoscopic disease activities and mucosal cytokines during remission in patients with Crohn's disease: a prospective study. Inflamm Bowel Dis. 2007;13(12):1493-1501.

5. Peterson KA, Byrne KR, Vinson LA, Ying J, Boynton KK, Fang JC, et al. Elemental diet induces histologic response in adult eosinophilic esophagitis. Am J Gastroenterol . 2013;108(5):759-766.

6. Mc Laughlin SD, Culkin A, Cole J, Clark SK, Tekkis PP, Ciclitira PJ, et al. Exclusive elemental diet impacts on the gastrointestinal microbiota and improves symptoms in patients with chronic pouchitis. J Crohns Colitis. 2013;7(6):460-466. doi: 10.1016/j.crohns.2012.07.009.

7. Horiuchi A, Nakayama Y, Sakai R, Suzuki M, Kajiyama M, Tanaka $\mathrm{N}$. Elemental diets may reduce the risk of aspiration pneumonia in bedridden gastrostomy-fed patients. Am J Gastroenterol . 2013;108(5):804-810.
8. Hartman C, Eliakim R, Shamir R. Nutritional status and nutritional therapy in inflammatory bowel diseases. World J Gastroenterol. 2009;15(21):2570-2578. doi: 10.3748/wjg.15.2570

9. Axelsson C, Jarnum S. Assessment of the therapeutic value of an elemental diet in chronic inflammatory bowel disease. Scand J Gastroenterol. 1977;12(1):89-95.

10. Brandse JF, van den Brink GR, Wildenberg ME, van der Kleij D, Rispens T, Jansen JM, et al. Loss of infliximab into feces is associated with lack of response to therapy in patients with severe ulcerative colitis. Gastroenterology. 2015; 149(2):350-355. doi: 10.1053/j. gastro.2015.04.016

11. Dotan I, Ron Y, Yanai H, Becker S, Fishman S, Yahav L, et al. Patient factors that increase infliximab clearance and shorten half-life in inflammatory bowel disease: a population pharmacokinetic study. Inflamm Bowel Dis. 2014;20(12):2247-2259. doi: 10.1097/MIB.

12. D'Haens G, Sandborn WJ, Feagan BG, Geboes K, Hanauer SB, Irvine EJ, et al. A review of activity indices and efficacy end points for clinical trials of medical therapy in adults with ulcerative colitis. Gastroenterology. 2007;132(2):763-786.

13. Neumann H. Endoscopic findings in ulcerative colitis. Video J Encyclopedia GI Endo. 2013;1(2):330-331.doi: doi.org/10.1016/ S2212-0971(13)70145-6

14. Walmsley RS, Ayres RCS, Pounder RE, Allan RN. A simple clinical colitis activity index. Gut. 1998;43:29-32. doi:10.1136/gut.43.1.29

15. Rutgeerts P, Sandborn WJ, Feagan BG, Walter Reinisch, Allan Olson, Jewel Johanns, et al. Infliximab for induction and maintenance therapy for ulcerative colitis. N Engl J Med. 2005;353:2462-2476. DOI: 10.1056/NEJMoa050516

16. Larsen PM, Raemussen D, Ronn B, Munk O, Elmgreen J, Binder V. Elemental diet: a therapeutic approach in chronic inflammatory bowel disease. J Inter Med. 1989;225(5):325-331.

17. Gassull MA, Cabre E. The Gastrointestinal Tract. In: Elia M, Ljungqvist O, Stratton RJ, Lanham-New SA, eds, Clinical Nutrition. 2nd ed. WileyBlackwell. 2007:176-192.

18. Rees RGP, Keohane PP, Grimble GK, Frost PG, Attrill H, Silk DBA. Elemental diet administered nasogastrically without starter regimens to patients with inflammatory bowel disease. JPEN. 1986;10(3):258262. 